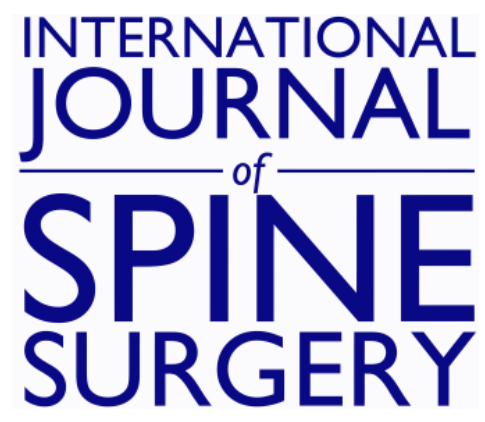

\title{
Foreword, Percutaneous and Endoscopic MIS Special Issue
}

\author{
Anthony T. Yeung \\ Int J Spine Surg 2014, 8 () \\ doi: https://doi.org/10.14444/1014 \\ http://ijssurgery.com/content/8/14
}

This information is current as of April 26, 2023.

Email Alerts Receive free email-alerts when new articles cite this article. Sign up at: http://ijssurgery.com/alerts 


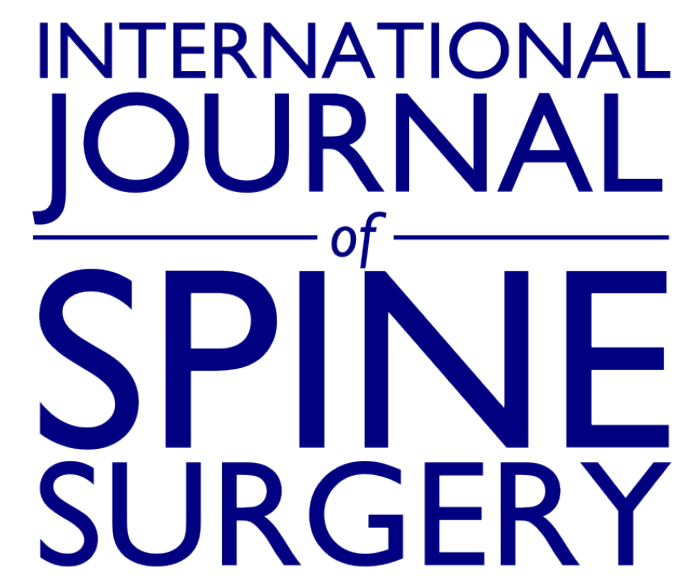

This article generously published free of charge by the International Society for the Advancement of Spine Surgery.

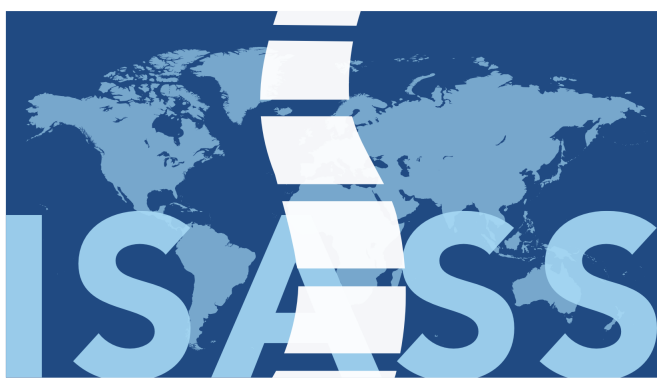

INTERNATIONAL SOCIETY for the ADVANCEMENT of SPINE SURGERY 


\section{Foreword, Percutaneous and Endoscopic MIS Special Issue}

Anthony T. Yeung, MD

Desert Institute for Spine Care, Phoenix, AZ, USA

Volume 8 Article 14 - Endoscopic \& Percutaneous Special Issue doi: 10.14444/1014

This special issue contains articles from authors that present their extensive level 3, 4, and 5 EBM experience treating back pain and sciatica. The authors either focus on the physiologic and anatomic source of pain, the methods used for "surgical pain management," or provide information on MIS surgical "pearls" on existing MIS surgical techniques.

These articles may be considered "controversial" by those who do not believe or use these techniques because it does not follow their conventional wisdom of established "gold standards" adopted by the old standards of open surgery by traditional surgeons.

Traditional thinking focuses on relieving compression, correcting deformity, or stabilizing the instability from an aging or injured spine and addressing the condition with the state of the art correction of a deformity to an ideal anatomic condition.

The world, however, has adapted to a myriad of nonsurgical treatments that provide quick enough relief that patients flock to these forms of treatment in order to avoid the open, more invasive surgical treatment. MIS interventionalist surgeons use these alternative treatments to reduce their patient's debilitating pain, even if temporarily, waiting for natural history, even years, to provide more lasting pain relief.

Treatment utilizing minimally invasive surgery and treatments of a non surgical nature is best delivered in a multi-disciplinary collegial environment of practioners, each with their area of expertise working together in a non-competitive financial environment focused on the individual needs of each individual patient. Treatment will then be a shared decision, along with the costs of each treatment.

With surgical treatment, the technical aspects may have great variability that depends on a critical surgeon factor where each surgeon will have a different set of skills, augmented by their surgical volume, technical skills, and experience, "the surgeon factor."

It may be difficult in our current environment where payors and institutions are dictating the type of care available by just focusing on managing costs, rather than managing care, sometimes under the guise of "evidence based medicine." This phrase, while appropriate and should be used as a guide, is now used for managing cost, not just care. In the long run, managing care designed for each individual patient in a collegial and cooperative environment will prove to be the most cost effective and beneficial model. This model has been set up at the University of New Mexico School of Medicine. 
I invite the readers to read each article with an open mind, cover- to- cover to appreciate some of the lesser known, but effective diagnostic and therapeutic treatment methods that offer relief to your patients with acute and chronic back pain and sciatica from injury or from an aging spine. These articles were accepted only after vigorous blinded reviews by recognized experts in their fields.

Copyright (C) 2014 ISASS - International Society for the Advancement of Spine Surgery. To see more or order reprints or permissions, see http://ijssurgery.com. 